\title{
Perceptions of ESL student tutors on challenges faced in peer tutoring
}

\author{
Ming Sing Chai, Siew Fong Lin \\ Faculty of Social Science, Arts and Humanities, Tunku Abdul Rahman University College, Kuala Lumpur, Malaysia \\ Email address: \\ chaims@acd.tarc.edu.my(M. S. Chai), linsf@acd.tarc.edu.my(S. F. Lin)
}

\section{To cite this article:}

Ming Sing Chai, Siew Fong Lin. Perceptions of ESL Student Tutors on Challenges Faced in Peer Tutoring. Education Journal. Vol. 2, No. 4, 2013, pp. 127-131. doi: 10.11648/j.edu.20130204.14

\begin{abstract}
The main purpose of this study is to discover the tutor's perceptions of challenges faced when performing simulation-based tasks. 50 Diploma in Business Administration students with mixed English proficiency in an institution of higher learning formed 10 groups in this study. The observations, interviews and diary entries used revealed that the tutors experienced a number of difficulties during the peer-tutoring sessions. They range from problems in the areas of communication, time management, group management, interest sustenance and lack of knowledge. It is important for instructors to be aware of the problems that student tutors face in the course of tutoring. The knowledge will enable them to improve and refine future peer-tutoring sessions which in turn, benefit both tutors and tutees.
\end{abstract}

Keywords: Peer Tutoring, Tutor, Tutees, Challenges

\section{Introduction}

Various forms of peer tutoring were reported in the literature with different terms being used interchangeably, such as peer-assisted learning, peer-mediated instruction and interventions, peer teaching, peer education, student team learning and so on $[1,2]$. The basic concept of peer tutoring involves student tutors teaching their peers and helping each other to learn through interactions among themselves. It can happen on a one-to-one basis or one-to-a few students. Regardless of how the peer tutoring is organized, social interaction is an important component in the process of peer tutoring as the interaction among tutors and tutees stimulate the development of cognition and construction of new knowledge. Naturally, people communicate and influence each other in the process of learning [3].

Peer tutoring has a long history of existence and was reported to be used as an alternative teaching method in school [1] as well as institutions of higher learning [4, 5]. In UK, the development of peer tutoring started in the late eighteenth century and has become part of the education system. There is an increasing awareness of the benefits of peer tutoring and increasing number of universities and colleges throughout UK integrating peer tutoring as part of the instructional method [4]. Unfortunately in Malaysia, peer tutoring which is learner-centered instruction, is still relatively new and not used widely. Very often, instruction in schools and colleges are teacher-driven whereby interaction among learners is minimal. Malaysian students, being rooted in Asian culture, are generally less engaging in activities that require interaction, less active in asking questions and reluctant to express opinions. Previous research showed that students lacked interpersonal, interaction and questioning skills during the early tutoring sessions [6]. This lack of involvement and interaction among learners could pose a challenge to tutors who are their peers since social interaction is very essential in peer tutoring. Therefore, a study on peer tutoring in the Malaysian context is important to examine the challenges faced by student tutors in using peer tutoring as an instructional method in institutions of higher learning.

\section{Literature Review}

Peer tutoring was found to be beneficial not only to the tutees but also to the student tutors. From the perspective of student tutor, the peer tutoring can help to improve presentation and teaching skills as reported by a medical student tutor teaching other medical students in peer-assisted learning: "Although it takes up a lot of time, it is very satisfying when a session goes smoothly. I think my presentation skills and teaching skills have improved." and in another experience "It creates an informal environment and can initiate a good discussion. On a personal level, I think I have gained a lot from being a peer-assisted learning 
tutor." [7].

Evidence showed that cross-year peer tutoring can enhance the academic development of student tutors among medical students [8]. In a research involving 447 final year medical students, the finding showed that $96 \%$ of students had played the role as student tutors at least once at some time during the program. The frequency of tutoring experience was found to be significantly related to students' overall academic achievement at the end of the program. It was suggested that the student who acts as a peer tutor has the opportunity of integrating the experience of a learner. Student tutors usually learn about the topic before they actually carry out the peer tutoring session [8]. As a result, the new information learned can be reinforced during the peer tutoring session. Furthermore, the interaction that occurs between tutor and tutees can stimulate cognitive growth that can result in better understanding and retention of information learned earlier [3].

In peer tutoring, the student tutors take on a helping and facilitating role. It was reported that student tutors can gain much from the experience of tutoring. They can develop confidence, communication skills and ability to facilitate and encourage the involvement of fellow students in activities which enable them to support each other's learning and make the learning experience more meaningful for both tutors and tutees [4]. In order to foster meaningful learning experience through peer tutoring, peer tutors need to master certain skills and overcome certain challenges during the peer-tutoring sessions.

Previous research has suggested that peer tutors who are effective are those with some subject-matter expertise in the area in which they are tutoring [9]. In peer tutoring, students learn through interaction with peers and also learn by imitation. Very often, peer tutors become the model for their peers to imitate and learn. Therefore peer tutors may feel the pressure to be the model for others to learn. There is a constant internal struggle to be better than others before one can teach. The challenges faced by peer tutors could come from within and outside of them such as the nature of the peer tutoring program.

According to Pugh [10], the effectiveness of a peer tutoring program may depend on the peer tutor mentor, program objectives, match between tutors and tutees, and learning goals. The peer tutor mentor acts in advising, taking charge to develop the program's scope, assigning tutees and setting objectives. In order to implement peer tutoring effectively, challenges faced by peer tutors need to be addressed. There has not been much research carried out on challenges faced by peer tutors from the perspective of peer tutors.

Solomon and Crowe [11] used qualitative methods to examine the experience of student tutors who were in the final semester of a physiotherapy program. The student tutors were asked to keep a reflective journal outlining their peer tutoring experiences for their peers in the same class. Content analysis of journals reflected nine thematic areas that were related to peer tutoring experiences from the perspective of peer tutors, covering both benefits enjoyed by peer tutors and challenges faced by them. Results of the analysis indicated that peer tutors struggled with their facilitation duties. They were concerned about their ability to ask appropriate questions that could lead to further understanding and their ability to determine the right timing for intervention during group discussion. Another struggle was student tutors having role conflicts in separating the role of student from that of tutor.

The challenges encountered by student tutors were not unexpected because skills are required to ask relevant questions and judge the appropriate timing for interventions. Sometimes, the challenges could be also caused by the lack of knowledge as reported by a student tutor in Hill, Liuzzi, and Giles [7]. In this peer assisted learning involving a medical student teaching other medical students, the student tutor reported "My initial trepidation was not having sufficient knowledge, and being asked questions that were beyond me. The most challenging aspect has been deciding what to include, and identifying the key knowledge and skills relevant for that stage".

Based on the literature review, it is obvious that most previous researches on peer tutoring focused on areas such as advantages of peer tutoring, effectiveness of peer tutoring but very few on challenges faced by peer tutors. Most of these researches were conducted in the West, involving students from the field of medicine [7, 11]. It has not been ascertained if the same scenario occurs among Malaysian students. Therefore, it is the aim of this research to look at peer tutoring from the perspective of tutors and to examine the challenges encountered by them in the local context.

\section{Methodology}

50 Diploma in Business Administration Year Two students participated in this study. Their age ranged from 19 to 20. They formed 10 groups, namely, Groups 1, 2, 3, 4, 5, 6, 7, 8, 9 and 10 for the peer-tutoring sessions. The 10 tutors for the groups were Ben (Group 1), Chen (Group 2), Lum, (Group 3), Tony (Group 4), Tricia (Group 5), Ling (Group 6), Gigi (Group 7), Charles (Group 8), Lily (Group 9) and Kenny (Group 10). In total, there were 6 male tutors and 4 female tutors involved in this study.

There were 5 tutees in each group. The group members in each group have mixed proficiency in English. The tutors were chosen based on their best proficiency in English within the group and also their willingness to become tutors. Their role was primarily assisting their tutees in performing 4 simulation-based tasks which were adapted from Ur [12].

"Stranded on an Island" was the first task. It required the tutees to imagine themselves shipwrecked on a tropical island. For their survival, they had to select 5 items out of 10 items listed out. The 10 items were canned food, a knife, a radio, a torch, matches, signal flares, first aid kit, a compass and a rope. 
The second task, "Choosing an Heir or Heiress", involved the tutees in choosing an heir or heiress after the death of a deceased but unmarried rich man. The heir or heiress should be selected out of 5 candidates who were Muthu, Kok, Adam, Halim and Kelly. In addition, particulars of the candidates were given to enable the students to make their decision.

5 family problems were provided in the third task, "May I Solve Your Problem?" Each group was given a problem to solve. The problems were on financial constraint, boy-girl relationship and friendship.

"Whom Should We Release?" was the final task. A criminal out of 5 criminals needed to be chosen to be released due to the problem of overcrowding in the prison. The criminals were Anne, Rahman, Samsaran, Salina and Wai Peng. Again, information on the criminals' crimes and family background were provided to aid the tutees in their decision making.

The respective groups spent 30 minutes on each task. Firstly, the students discussed the simulation and finally, made a group decision on it backed up with much-supported points. Additionally, they were required to have an in-class presentation of the group's choice of decision.

Their peer tutoring sessions were video-taped to facilitate observations to be carried out. In addition, both the tutors and tutees were interviewed and wrote diary entries describing their experiences. The different research methods provided triangulation of data required for this study.

\section{Findings}

There were numerous challenges faced by the tutors during their sessions. They experienced difficulties in communication, time management, group management, interest sustenance and lack of knowledge. Sadly, these problems left behind a negative impact on the teaching and learning process in the course of the peer-tutoring sessions.

\subsection{Communication}

5 tutors faced difficulties in their communication with their tutees. It was a two-way situation in which both the tutors and tutees could not comprehend each other. Ben, Tricia and Charles encountered problems in understanding their tutees while Chen and Ling faced problems in having their tutees following their teaching.

Ben, Tricia and Charles found it an uphill task in attempting to understand their tutees' questions. They needed more time to answer their enquiries which frustrated both parties tremendously. Tricia realised that it was due to the tutees' poor command in English which caused them to be unable to follow their teaching initially. Consequently, they had to ask questions at the end of the peer-tutoring sessions but again, were unable to form their questions clear enough for their tutors. However, Chen and Ling were unable to clarify themselves to their tutees. Both of them admitted that it could be due to their lack of fluency in spoken English.

\subsection{Time Management}

6 tutors complained that they were not given enough time to perform the tasks. Ben, Lum, Tony, Tricia and Ling struggled to help their groups get prepared for their class presentation of their decisions at the end of the discussions. There were too many different opinions obtained from the tutees and too little time to have thorough discussions of them.

Both tutors and tutees had different opinions on the criminal to be released in the fourth simulation, "Whom Should We Release?" Initially, a majority of them were sceptical in choosing a candidate because they felt that criminals should not be released easily for they had committed serious crimes. However, when they realised that they had to choose a candidate, they came up with different choices.

Consequently the groups argued for a long time over the final selection of candidate because they could not convince their group members to accept their choice. They felt that they did not have enough time to have productive discussions. Ben, Tony and Tricia admitted that their groups could not reach consensus in their decision making. Finally, they allowed their respective group presenters to present their own choice of criminals to be released despite not obtaining overall approval from their groups to do so.

\subsection{Group Management}

6 tutors in this study encountered difficulties in managing their groups. They were Ben, Chen, Charles, Lum, Lily and Tony. The challenges they had were disrespectful tutees and constantly-absent tutees and undisciplined behaviour. Group facilitation can be a form of challenge to student tutors [11].

All 6 of the tutors had their peer tutoring sessions affected adversely by disruptive, opinionated and argumentative tutees. It was due to their disagreements with the tutors over their views in 3 simulations which were "Choosing an Heir or Heiress", "May I Solve Your Problem?" and "Whom Should We Release?" Lum and Chen were observed to be unable to handle their tutees due to their shy and quiet nature. However, Ben, Charles, Lily and Tony could manage their tutees successfully. It could be due to their assertive and confident demeanour.

Ben and Chen had problems with constantly-absent tutees. They did not have complete groups to tutor after their first simulation. It was observed that the same students missed their sessions without providing reasons for their absence.

Furthermore, Lum, Chen and Lily complain of their tutees' undisciplined behaviour. They did not participate in the discussions but spent the time completing assignments for other courses and making fun of their friends' views. Their behaviour frustrated their group members tremendously.

\subsection{Interest Sustenance}

5 tutors, Chen, Lum, Tony, Tricia and Charles confessed that they were unable to sustain their groups' interest in the 
tasks. It resulted in the tutors instead of the tutees presenting their groups' decisions after the peer tutoring. The tutees displayed their lack of interest by not actively participating in the discussions and leaving the final group decision making to their tutors.

It was observed that the tutees were active in the first simulation, "Stranded on an Island". Later, they started to lose interest in the rest of the simulations. They became passive and uninterested in the discussions. Tony commented that the simulations required common-sense knowledge and therefore, his tutees found them unchallenging. Chen, Lum and Tony resorted to "helping" their groups by writing down points for their groups to present without much high-level discussions.

\subsection{Insufficient Knowledge}

5 of the tutors admitted that they lacked knowledge when facilitating their sessions. The tutors involved were Ling, Gigi, Tricia, Charles and Kenny. This concurs with the discovery that some tutors merely deliver knowledge instead of developing it for the benefit of their tutees as reported in Roscoe and Chi [13]. The tutors' insufficient knowledge in this study had caused some of their tutees to lose faith in their tutoring. Likewise, some tutees may even resort to working harder on their own to compensate for the tutor's lack of knowledge [14].

Ling discovered that her group could not have productive discussions due to the lack of input from her. Gigi and Tricia found that they should have researched more on inheritance laws in Malaysia for the second task, "Choosing an Heir or Heiress" and counseling strategies for the third task, "May I Solve Your Problem?" to help them play their role effectively as tutors. On the other hand, Kenny had some helpful tutees who researched by using their smartphones so that their group could have useful information to help them in their task.

\section{Conclusions}

The challenges faced by the tutors in this study were in the areas of communication, time management, group management, interest sustenance and insufficient knowledge. These problems resulted in some tutors losing their enthusiasm in teaching and level of confidence in playing their roles. Simultaneously, the problems, too, had resulted in the loss of focus and participation from some of the tutees during the peer-tutoring sessions.

Therefore, it is important for tutors to be well prepared for their roles. This can be achieved through providing training for tutors [15]. Training in the form of workshops on language enhancement, lesson planning, confidence boosters, appropriate behaviour [16] and classroom management can be carried out. Through the training, the tutors will become more committed and aware of the impact of their actions on their tutees. In addition, new tutors can be paired with experienced ones so that the former can learn from their respective partners [17].

\section{References}

[1] Boudouris, C. C. "Peer-tutoring: Positive peer interactions," Ohio Reading Teacher, 37(1), 11-19, Fall 2005. [Online]. Available: http://search.proquest.com/docview/209604759. [Accessed Dec 2, 2012].

[2] Henning, J. M., Weidner, T., and Jones, J. "Peer-assisted learning in the athletic training clinical setting," Journal of Athletic Training, 41(1), 102-108, 2006. [Online]. Available: http://search.proquest.com/docview/206646996. [Accessed Dec 2, 2012].

[3] Qureshi, M.A. and Stormyhr, E. "Group dynamics and peer-tutoring a pedagogical tool for learning in higher education," International Education Studies, 5 (2), 118-124, Apr. 2012. [Online]. Available: http://search.proquest.com/docview/1009899663. [Accessed Dec 2, 2012].

[4] Potter, J. "New directions in student tutoring," Education \& Training, 39 (1), 24-29, 1997. [Online]. Available: http://search.proquest.com/docview/237075688. [Accessed Dec 2, 2012].

[5] Chen, C., \& Liu, C. "A case study of peer tutoring programme in higher education," Research in Higher Education Journal, 11, 1-10, 2011. [Online]. Available: $\mathrm{http} / / /$ search.proquest.com/docview/877024941. [Accessed Dec 2, 2012].

[6] Ismail, H. N. and Alexander, J.M. " "Learning within scripted and nonscripted peer-tutoring sessions: The malaysian context," The Journal of Educational Research, 99 (2), 67 77, Nov/Dec 2005.

[7] Hill, E. Liuzzi, F. and Giles, J. "Peer-assisted learning from three perspectives: student, tutor and co-ordinator," Clinical Teacher, 7(4), 244-246, Dec. 2010. [Online]. Available: DOI: 10.1111/j.1743-498X.2010.00399.x. [Accessed Mar 2, 2013].

[8] Sobral, D. T. "Cross-year peer tutoring experience in a medical school: conditions and outcomes for student tutors," Medical Education, 36(11), 1064-1070, Nov.2002, [Online]. Available:DOI: $\quad$ 10.1046/j.1365-2923.2002.01308.x. [Accessed Mar 2, 2013].

[9] Schmidt, H. and Moust, J. "What makes a tutor effective? A structural-equations modeling approach to learning in a problem-based curriculum," Academic Medicine, 70, 708 714, 1995.

[10] Pugh, K. H. "Peer tutoring do's and don'ts," Phi Delta Kappan, 86 (8), 631-631, 2005. [Online]. Available: http://search.proquest.com/docview/218481417. [Accessed Dec 2, 2012].

[11] Solomon, P. and Crowe, J. "Perceptions of student peer tutors in a problem-based learning programme," Medical Teacher, 23 (2), 181-186, Mar. 2001. [Online]. Available: DOI: 10.1080/01421590020031101. [Accessed Mar 2, 2013]

[12] Ur, P. Discussions that work, Cambridge University Press, Cambridge, 1987.

[13] Roscoe, R. D. and Chi, M. T. H. "Understanding tutor learning: Knowledge-building and knowledge-telling in peer tutors' explanations and questions," Review of Educational 
Research, 7, 534-574, Dec. 2007.

[14] Moust, J. and Schmidt, H. "Comparing students and faculty as tutors: How effective are they?" in P. Bouhuis (ed.), $P B L$ as an Educational Strategy, Network Publications, Maastricht, 1993,121-134.

[15] Gaustad, J. "Peer and cross-age tutoring", ED354608, ERIC Clearinghouse on Educational Management Eugene OR, 1993.
[16] Schwartz, D., Blair K., Biswas G., Leelawong, K. and Davis, J. "Learning with animation: Research and implications for design, animations of thought: Interactivity in the teachable agent paradigm", in Lowe R. and Schnotz W' (eds), Cambridge University Press, Cambridge, 2007.

[17] Coenen, M. E. "Using gifted students as peer tutors", Gifted Child Today, 25, 48-55, Jan. 2002. 